\title{
Arbor
}

\section{El hispanismo en México, América Central y Las Antillas}

\author{
Rebeca Barriga Villanueva y Pedro Martín Butragueño
}

Arbor CLXVIII, 664 (Abril 2001), 513-532 pp.

\section{¿Un nuevo hispanismo?}

Nuestro propósito en este trabajo es ofrecer un panorama representativo ${ }^{1}$ del desarrollo del hispanismo en México, Cuba, Puerto Rico, República Dominicana, Guatemala, Honduras, El Salvador, Nicaragua, Costa Rica y Panamá en la última década. A partir del estudio de este presente, esperamos poder marcar el sentido de las líneas de interés futuras. El desarrollo de la investigación hispanística en estos países no es el mismo. Claramente, el número de trabajos es mayor en México, Cuba, Puerto Rico y Costa Rica - lo que no significa la ausencia de figuras o estudios destacados en otros lugares- ${ }^{2}$. El caso cubano parece quedar aparte. Su aislamiento ideológico y económico ha venido repercutiendo en los alcances de la investigación. Salvo quizá en México y Puerto Rico, la lejanía con los modelos teóricos y los avances técnicos más recientes es evidente en la mayor parte de los trabajos lingüísticos realizados en la América Media ${ }^{3}$. Los estudios de dialectología, lexicologia y sintaxis, en general, se apoyan en referencias bibliográficas hispánicas tradicionales o estructuralistas, clásicas pero muchas de ellas ya superadas.

Es difícil sostener que la extensa región comprendida al sur del río Bravo y al norte de las costas de América del Sur, en la que viven los habitantes de una decena de países hispanos, forme una sola entidad cultural ${ }^{4}$. Más difícil todavía es pensar que la investigación hispanística llevada a cabo en tan vasta región sea fruto de las relaciones directas o de la colaboración personal o institucional. Es verdad que uno de los pioneros del estudio de la lengua y la literatura en México fue el dominicano Pedro Henriquez Ureña ${ }^{5}$, y también es verdad que 
las relaciones entre México y Cuba han sido y siguen siendo intensas. Pero también es cierto que América Central sigue estando muy lejos de México. Sin embargo, es posible que varias circunstancias comunes, en particular la asimétrica relación con los Estados Unidos, expliquen ciertas convergencias y divergencias del pensamiento hispanista en varios de estos países.

Pero, ¿se puede seguir hablando de hispanismo cuando hemos asistido a una separación de lo filológico en estudios filológico-literarios $\mathrm{y}$ en estudios lingüísticos, que pasan a tener el lenguaje como objeto de estudio? ${ }^{6}$. A grandes rasgos, el hispanismo en el área que estamos reseñando ha tenido dos grandes facetas, parcialmente traslapadas. En la primera, el objetivo central de los estudios ha sido la descripción del español de cada país americano, en sus manifestaciones lingüísticas y literarias. La tesis central de este hispanismo es la unidad en la diversidad, así que podríamos decir que descansa en la idea del consenso. Los estudios descriptivos buscan incorporar sus datos a comunidades cada vez más amplias. Hablamos del español de Veracruz en la medida en que existe un español de México, que a su vez se incorpora al español americano, y éste al español general o internacional. Es decir, el sentido ascendente de la interpretación de los datos tiende a subrayar su esencia hispánica.

En la otra faceta, el hispanismo da cabida a la presencia del elemento indígena ${ }^{7}$, criollo y negro ${ }^{8}$, que en América determinan rasgos peculiares de la investigación ${ }^{9}$. El punto de partida de esta perspectiva es la idea de conflicto, entendido como el análisis de los procesos -y no sólo los resultados- del contacto entre lenguas y culturas: bilingüismo, desplazamiento, extinción y surgimiento de nuevos valores ${ }^{10}$. Las generalizaciones sobre los datos obtenidos dentro del paradigma del conflicto adoptan un sentido descendente en la estructura social, acentuando las diferencias antes que las similitudes ${ }^{11}$. Esta realidad está en la base de la caracterización del hispanismo desarrollado en nuestra área.

Si entendemos por hispanismo tradicional el dedicado a estudiar las grandes producciones lingüísticas y literarias de la Edad Media y de los Siglos de Oro ${ }^{12}$, ése no sería el más representativo de la que hemos llamado América Media. Ello no quita que en los últimos años el trabajo filológico haya madurado y que varios especialistas estén publicando trabajos notables. Pero lo distintivo de la región ha sido la gestación de realidades encontradas: el nacimiento del español americano ${ }^{13} \mathrm{y}$ el alumbramiento de culturas y de literaturas mezcladas, criollas o mestizas ${ }^{14}$. 


\section{El hispanismo en México, America Central y Las Antillas}

A lo largo del último tercio del siglo XX se llevó a cabo un amplio programa descriptivo. Los grandes proyectos sincrónicos

precedieron a los históricos. Poco a poco se obtuvo la base indispensable para emprender otro tipo de trabajos y, al tiempo, hubo cuadros de investigadores formados en esos mismos proyectos, los mismos investigadores que poco más adelante iban a abrir camino a preocupaciones diferentes, a veces bajo enfoques teóricos radicalmente distintos.

\section{La teoría literaria y la teoría lingüística}

El interés por la teoría literaria ha aumentado globalmente. En las revistas caribefías, mexicanas y centroamericanas es fácil encontrar trabajos más o menos divulgativos sobre la teoría de la intertextualidad, el desconstruccionismo, la sociocrítica, la crítica marxista, el psicoanálisis, los análisis de género, las ideas de Foucault o de Eco. Sin embargo, aún no se alcanza la madurez necesaria para ofrecer propuestas originales; por momentos, se propagan modas que no llegan a cuajar en cuerpos teóricos permanentes. Quizá el escrito más importante sea $E l$ arco y la lira de Octavio Paz (ahora incluido en el vol. I de sus Obras completas), en el que se conjuntan el idealismo, la estilística y el estructuralismo clásicos.

También en lingüística domina el eclecticismo. Un caso ilustrativo es el del desarrollo de la gramática generativa. En México, la teoría se conoció desde los primeros momentos. Pero hay que esperar hasta fines de los años ochenta para encontrar trabajos de peso realizados dentro de este marco. A lo largo de los años noventa la teoría se instala en contados departamentos de investigación, con un crecimiento mucho menor de lo que se esperaba una década antes. Más que el paradigma dominante, aparece como una opción teórica más. El mayor interés parece haberse dado en Puerto Rico, donde Humberto López Morales tuvo el doble papel de difusor del generativismo y de la sociolingüística variacionista. En Cuba y sobre todo en Costa Rica el generativismo es marginal. Pero en conjunto, aunque la influencia de las teorías norteamericanas es tan decisiva como en casi todas partes, ninguna de ellas se ha asentado de manera excluyente.

Aunque la idea pueda matizarse, la convivencia de varias teorías no debe entenderse igual en lingüística que en literatura. Entre los lingüistas, hay quienes trabajan en gramática generativa, en gramática cognoscitiva, en diferentes modelos funcionalistas, etc., pero suele haber una coherencia personal: el eclecticismo es el efecto de conjunto. Es 


\section{R. Barriga Villanueva y P. Martín Butragueño}

probable que la situación en los estudios literarios no sea la misma. Aparentemente, el eclecticismo sí llega a ser individual.

\section{Estudios sincrónicos}

A lo largo de los años noventa se han terminado o han llegado a una etapa de madurez varios grandes proyectos descriptivos, y otros más han ido tomando cuerpo y se encuentran en diferentes grados de avance.

La investigación que mejor representa el paradigma del consenso, de la búsqueda de la unidad en la variedad, es la de la norma culta de las principales ciudades del mundo hispánico, iniciada en 1964. Este proyecto tuvo desde el principio su mentor en Juan M. Lope Blanch y rindió sus primeros frutos en México ${ }^{15}$. En la América Media se ha extendido a las ciudades de San Juan de Puerto Rico, San José de Costa Rica y La Habana ${ }^{16}$. A partir del análisis de sus materiales se han venido haciendo trabajos descriptivos en casi todos los planos de la lengua, en especial en el sintáctico y en el léxico ${ }^{17}$. A la luz de este ambicioso proyecto, se han emprendido varios estudios de alcance más local; tal es el caso del habla de Sinaloa, México (López Berríos y Mendoza Guerrero 1997).

En México, está virtualmente terminada la publicación de los seis tomos del Atlas Lingüístico de México, dirigido por Juan M. Lope Blanch, cuyo objetivo es dar cuenta de las zonas dialectales del país en los principales niveles de lengua. Además de su valor intrínseco, en este proyecto ha participado una generación importante de lingüistas, en un ciclo que abarca una treintena de años. Supone un hito esencial del desarrollo de la hispanística en México. Más recientemente, la América Media ha quedado incluida en el Atlas Lingüistico de Hispanoamérica, dirigido por Manuel Alvar y Antonio Quilis, y que está cartografiando a gran escala la diversidad del español americano. En Costa Rica, Quesada Pacheco ha publicado un «Pequeño Atlas lingüístico de Costa Rica» (1992). La metodología del Atlas Lingüístico de Cuba aparece descrita en García Riverón 1991.

Otros proyectos de gran envergadura son los lexicográficos. Entre ellos destaca el del Diccionario del español de México, dirigido por Luis Fernando Lara, del cual ya se han publicado las versiones básica, fundamental y usual, partes del gran diccionario que se encuentra ya en su fase final. Esta obra se basa en un corpus de diversos registros de lengua hablada y escrita, seleccionado con criterios estadísticos. 


\section{El hispanismo en México, America Central y Las Antillas}

En Costa Rica, Quesada Pacheco publicó en 1991b un Nuevo diccionario de costarriqueñismos; véase también Sánchez Corrales 1998 sobre el «Nuevo diccionario del español de Costa Rica» ${ }^{18}$.

El proyecto de estudio del español en los medios de comunicación (DIES-RTP), dirigido por Raúl Ávila, da cuenta de las semejanzas y diferencias lingüísticas en radio, televisión y prensa. Se están tomando muestras de Hispanoamérica y de España. En nuestra zona, además de en México, se está trabajando en Cuba, Puerto Rico, República Dominicana, Costa Rica y Panamá.

El corpus lingüístico afrocubano puede ser un buen ejemplo de investigación interesada en el conflicto, pues parte de consideraciones sociolingüísticas sobre las lenguas en contacto: "Antes del surgimiento de los estudios de las lenguas en contacto, todas aquellas manifestaciones lingüisticas que no se correspondían con las lenguas formalmente institucionalizadas eran consideradas variedades corrompidas, aberrantes, simplificadas e incompletas» (Ortiz López 1998, p. 27). Sobre esta misma línea, cabe mencionar los trabajos de Lydia Cabrera, Germán de Granda y Manuel Alvarez Nazario.

Una posible interpretación del desarrollo de los grandes proyectos descriptivos en la década de los años noventa es la visible tendencia hacia la investigación interesada en lenguas en contacto. Hay una diferencia en la perspectiva con que se ve al español. Ya no es la lengua que domina el área y que nos unifica, sino la lengua que está en relación con las otras lenguas de su contexto ${ }^{19}$.

\section{Estudios históricos}

La década de los años noventa ha presenciado el desarrollo de los estudios históricos locales; con seguridad, en los próximos años el campo seguirá creciendo. La historia del español americano y la historia de las relaciones entre el español y otras lenguas empieza a cuajar en varios volúmenes realmente interesantes. Para Honduras es imprescindible el libro de Atanasio Herranz sobre Estado, sociedad y lenguaje (1996), en el que se examina el período colonial, la época independiente y la situación pretérita y actual de los grupos étnicos. En Costa Rica, Quesada Pacheco publicó ya en 1990 un volumen sobre el español colonial, y en 1991a buena parte de su libro sobre El español de Guanacaste incluye información histórica ${ }^{20}$.

En México se ha venido señalando desde hace mucho la necesidad de emprender estudios históricos de gran aliento. Sin embargo, ha 
habido que esperar prácticamente a la última década para concretar ese interés. En 1994 aparecieron los Documentos lingüísticos de la Nueva España (Company 1994), fuente para la descripción de diferentes estadios del español mexicano ${ }^{21}$. Ya en 1985 Lope Blanch había publicado El habla de Diego de Ordaz, que abre esta tradición, seguida muy de cerca por Claudia Parodi, quien con sus Orígenes del español americano (1995) realiza un trabajo de reconstrucción fonológica, y por Beatriz Arias, que en El español de México en el siglo XVI hace un estudio filológico de quince documentos. Actualmente, está en curso un proyecto propiciado por Concepción Company y José Lema cuyo objetivo es redactar una sintaxis histórica del español.

En Puerto Rico, destaca la labor de Manuel Álvarez Nazario, quien en libros como El habla campesina del país: orígenes y desarrollo del español en Puerto Rico, de 1990, y en la Historia de la lengua española en Puerto Rico, de 1991, examina los varios elementos que forman la historia del español local.

El interés por la historia de la lingüística también es muy reciente. El desarrollo historiográfico es en sí mismo una prueba de la madurez de una disciplina ${ }^{22}$. Quesada Pacheco (1991c) publicó una historia de los estudios filológicos y lingüísticos en Costa Rica. Herranz 1990 hace un recuento de los estudios sobre el español de Honduras. En México, son notables los esfuerzos de Ascensión Hernández de León Portilla, Ignacio Guzmán Betancourt, Bárbara Cifuentes y Thomas Smith-Stark, que trabajan en diversos momentos de la historia de la lingüística de este país. Rebeca Barriga Villanueva y Claudia Parodi publicaron en 1998 un volumen sobre La lingüistica en México 1980-1996, que da cuenta de la gran expansión de la investigación lingüística en los últimos años.

En cuanto a la historia de la literatura, falta todavía una seria renovación en su contenido y en su concepción misma. En muchos aspectos parece seguir siendo necesario apoyarse en obras algo esquemáticas, como la Historia de la literatura costarricense (1967), de Abelardo Bonilla, el Desarrollo literario de Toruño (1957) dedicado a El Salvador, o el Panorama del mismo país de Gallegos Valdés (1962), o para Panamá en los trabajos de Rodrigo Miró (1971) o Ismael García S. (1972). Quizá más interesantes y renovadores en sus perspectivas son libros como el de Flora Ovares et al., La casa paterna. Escritura y nación en Costa Rica_(1993), en el que en varios ensayos independientes se estudia la evolución cultural y literaria costarricense; la Historia del teatro en El Salvador - hemos visto el t. I, de la Colonia a 1900-, de Carlos Velis, en el que se parte del teatro como hecho histórico, 


\section{El hispanismo en México, America Central y Las Antillas}

se revisa el estado de la crítica y se analizan tres textos; este último manual es introductorio, pero contiene información útil. Para Guatemala, puede verse la Historia de Albizúrez y Barrios 1993.

En México, como en otros lugares de nuestro ámbito, se escriben por lo menos dos clases de historia de la literatura. Más esquemáticas son la Historia de Carlos González Peña (1928) o la de Julio Jiménez Rueda (1928). Por otra parte, están los intentos más recientes de dar cuenta del desarrollo de las literaturas mexicanas (Garza Cuarón y Baudot 1996). En la Universidad Nacional Autónoma de México y en El Colegio de México existen proyectos para editar críticamente textos literarios novohispanos, como los de Fernán González de Eslava, fray Joaquín Bolaños, fray Toribio de Benavente y sor Juana Inés de la Cruz, entre otros.

La literatura cubana ha sido examinada en varias historias. El manual de Raimundo Lazo (1974), de corte tradicionalista, dividía la historia literaria cubana en cuatro períodos, intentando correlacionarlos con las motivaciones históricas. Frente a este tipo de historias, encontramos el Recuerdo a [sic] de Fernández Retamar, inserto en un marco ideológico posrevolucionario. En cuanto a la literatura dominicana, puede verse la revisión de 1965 a 1985 de Alcántara.

¿Se está pasando en la América Media de la historia literaria tradicional o muy tradicional a otra más abierta, más apoyada en el análisis ideológico, crítico y social? Probablemente sí, y ello, en principio, es bueno. Quizá uno de los peligros es la tentación de caer en lugares comunes del desarrollo de la cultura, sobre todo cuando falta en muchas partes investigación básica que dé a conocer obras, autores y elementos culturales aún no considerados ${ }^{23}$.

\section{El análisis de la literatura contemporánea}

Si bien es cierto que el Medievo y los Siglos de Oro siguen siendo de interés común, en los últimos años se ha acentuado el estudio de la literatura contemporánea en nuestra área. La posmodernidad se ha convertido en el eje temático de muchos trabajos. Junto a los topoi clásicos, se da ahora una llamativa insistencia en problemas como la relación entre oralidad y escritura, la cultura de masas o el papel de la mujer en la creación literaria ${ }^{24}$.

Aunque dos marcos ideológicos diferentes parecen subyacer a la visión de las críticas literaria cubana y puertorriqueña, ambos países parecen converger en la búsqueda de identidad y de tradiciones ${ }^{25}$, en 
una versión específica de la posmodernidad ${ }^{26}$. Se ha llegado a afirmar que tal búsqueda origina el desarrollo de un canon ${ }^{27}$. También Centroamérica parece inmersa en la búsqueda de la definición, continental y nacional ${ }^{28}$. Esta situación se va a reflejar en el estudio literario y lingüístico, y da albergue al mencionado paradigma del conflicto, entendido a veces como reapropiación del espacio cultural (Ortega 1991).

El estudio detallado de la literatura contemporánea se ha ido asentando cada vez con mayor fuerza en los últimos años en Centroamérica ${ }^{29}$. Un ejemplo de ambición editorial es la publicación en Costa Rica de los cinco tomos de las Obras completas de Fabián Dobles (1993); gran repercusión ha tenido la obra poética de la panameña Diana Elisa Morán Garay (cf. 1989a, 1989b y el Homenaje de 1990). Autores como Augusto Monterroso (guatemalteco, pero exiliado en México desde 1944) han sido estudiados también en sus países natales (cf. Pineda Reyes 1989). En cuanto a Miguel Ängel Asturias, en 1999 se cumplieron cien años de su nacimiento (cf. Hurtado Heras 1997).

Resulta difícil sintetizar las grandes líneas de la creación y la crítica literaria en México. Junto a ediciones de Juan Rulfo, Octavio Paz, Carlos Fuentes, José Emilio Pacheco o Fernando del Paso, son ya innumerables los artículos, libros y tesis publicados en los últimos años. Los protagonistas de la literatura contemporánea son, además de los citados, José Revueltas, Emilio Carballido, Sergio Pitol, José Agustín, Juan José Arreola, Elena Garro, Juan Villoro, Jaime Sabines, Alí Chumacero, entre otros nombres.

Un género que parece abrirse paso entre la contradictoria condición social y política de varios de los países de la América Media es la literatura testimonial, a caballo entre el relato y la crónica, entre las letras y la sociología, entre el exilio y la revolución. Véase por ejemplo Román-Lagunas $1994^{30}$ sobre el nicaragüense Omar Cabezas y la guatemalteca Rigoberta Menchú, o el libro de Ochando Aymerich 1998 sobre la escritura testimonial en Cuba.

No siempre es fácil conseguir publicaciones literarias de Centroamérica, así que las antologías se vuelven herramienta indispensable. Alvaro Quesada et al. publicaron en 1993 una Antología del teatro costarricense 1890-1950, que probablemente es la mejor introducción al tema, partiendo de la búsqueda de un teatro nacional, que evoluciona después hacia las nuevas tendencias, en el marco del desarrollo de los escenarios y los espectáculos ${ }^{31}$. Para Honduras, resulta de gran utilidad la antología de cuentos a cargo de Jorge Luis Oviedo reimpresa en 1993, y la de sonetos de Elvir Rojas. La poesía salvadoreña está representada con amplitud en el Índice de Galindo (2a. ed., 1987), y 
también en Guillén 1989. A su vez, Morales Santos 1990 da una visión del desarrollo de la poesía guatemalteca.

Dos antologías de la narrativa y el cuento mexicano son, respectivamente, la de Domínguez Michael 1989 y Zavala 1998. El cuento cubano está representado en El submarino amarillo, antología de Padura 1994, y el puertorriqueño en Apalabramiento, de Barradas 1983, y en la Antología alterna de Rosado 1995. Para la poesía juvenil cubana puede verse la antología de Lázaro y Zamora 1994, que se proponen reunir a todos los poetas nacidos después de 1940 que viven fuera o dentro de la isla. La identidad cubana se reafirma en el exilio (cf. la antología poética de Elías Miguel 1988)32, verdadero leiv-motiv de esta literatura.

\section{Culturas mezcladas}

La mezcla cultural explica el desarrollo de un hispanismo con caracteres particulares en el área que estamos describiendo ${ }^{33}$. La presencia del elemento indígena en México y parte de Centroamérica, y de población afroamericana en el Caribe insular y continental trae como consecuencia lógica un contacto de lenguas que se manifiesta en problemas diferentes, vinculados unos al sistema lingüístico y otros a los hablantes: procesos de pidginización, lenguas criollas, bilingüismo, alternancia de códigos, préstamos, política lingüística, actitudes, enseñanza de primeras y segundas lenguas. Esta realidad ha motivado trabajos de diferente índole en distintas zonas. En un principio, estos problemas han interesado más a indigenistas y criollistas extranjeros, antes que a los hispanistas locales. ¿Está cambiando esta situación? La respuesta es con claridad afirmativa, quizá porque cada vez más los interesados en el español o en las lenguas indígenas tienden a considerarse simplemente lingüistas.

Los estudios sobre lenguas o elementos criollos cuentan ya con cierta tradición. Como marco general, son muy útiles los trabajos de Germán de Granda de 1987 y 1994. El Caribe está bien representado en varios libros recientes: Perl y schwegler editaron en 1998 un volumen sobre la América negra, y en el mismo año Ortiz Lópe recoge varios trabajos escritos en marcos teóricos diferenciados sobre el Caribe hispánico (1998a) y publica un libro sobre las Huellas etno-sociolingüísticas bozales y afrocubanas (1998b). Deben también destacarse las publicaciones costarricenses sobre el criollo de Limón ${ }^{34}$ y el trabajo de Lipski 1989 sobre los negros congos de Panamá. 
La fuerza de la realidad bilingüe ha ocasionado que surjan posturas controvertidas entre hispanistas e indigenistas. El problema del contacto entre el español y las lenguas indígenas puede verse de maneras muy distintas, y llegar a conclusiones radicalmente opuestas según el tipo de fenómenos en que se detenga la investigación. Si se piensa que el contacto sólo toma cuerpo a través de préstamos léxicos o morfosintácticos, la investigación tiende a minimizar la relación entre las lenguas. Pero si se hace hincapié en los hablantes y se realizan estudios sociolingüísticos en comunidades concretas, los resultados son muy diferentes. Este segundo tipo de trabajos ha comenzado a tener fuerza en esta última década ${ }^{35}$.

\section{Hacia el futuro}

El hispanismo americano comenzó interesándose en la dialectología y en el estudio de los clásicos, al tiempo que la distancia entre lingüistas y críticos literarios era salvable. Hoy la distancia se sigue agrandando, y el centro de atención se ha trasladado de las grandes divisiones geográficas a las ciudades, y del estudio del pasado literario a la contemporaneidad. Pocos hispanistas — menos cuanto más jóvenes- se atreven hoy día a frecuentar de igual forma los estudios lingüísticos y los literarios. Sólo en el análisis del discurso parece haber ciertas connivencias. Todo parece apuntar a una mayor especialización. $\mathrm{Cu}-$ riosamente, los críticos han ampliado su campo de interés, y han estado analizando muchos documentos que antes no se hubieran considerado literarios. Los lingüistas, en cambio, han dado prioridad a los textos no literarios y se han retirado de áreas que antes sí exploraban, en particular del estudio del estilo, es decir, de los rasgos lingüísticos de la lengua literaria.

Para el futuro, la cuestión es saber cuáles son los límites del proceso de especialización. En nuestros países existe un límite asociado al volumen del cuerpo académico, al número de estudiosos y de departamentos universitarios. Por un lado, es cierto que algunos campos están creciendo muy rápido. En México, por ejemplo, el ritmo de publicaciones lingüísticas aumentó geométricamente en la última década, pero el número de lingüistas sólo aumentó de manera aritmética. Por otra parte, la interdisciplinariedad es un hecho en varias áreas de trabajo: en los estudios psico-, neuro-, etno- y sociolingüísticos, en lenguaje y educación, en el estudio sobre las políticas del lenguaje; lo mismo 
ocurre con la sociología de la literatura, la sociocrítica o la enseñanza de la literatura.

La enseñanza de lenguas y en general la lingüística aplicada parece ser uno de los campos en más clara expansión. En la enseñanza de lenguas, la mayor parte de los trabajos se orientan en uno de estos tres terrenos: el español como lengua materna, el español como segunda lengua para hablantes de lenguas indígenas y el inglés como segunda lengua. Aunque se siguen publicando todavía muchos trabajos superficiales, la calidad general parece estar mejorando rápidamente, aunada a una fundamentación teórica sustantiva. Sorprende, sin embargo, el escaso interés mostrado por los gobiernos hispanoamericanos en la planificación de la enseñanza del español como segunda lengua, tomando en cuenta el creciente peso político, económico y sociocultural del español en el mundo.

Más allá de los avances teóricos y metodológicos y de la aparición de nuevas disciplinas, subsisten en varios países fuertes deficiencias Ciescriptivas. Se conoce tan poco de El Salvador, Nicaragua o Panamá, que se hace difícil imaginar un desarrollo consistente de la investigación hispanística si no se dispone de una base descriptiva mínima ${ }^{36}$. Ya no se puede decir hoy día que el español de México, Cuba o Puerto Rico sean grandes desconocidos. Contamos ya con descripciones de conjunto, y aunque falte ordenar muchos de los detalles, es poco probable que la investigación meramente descriptiva vaya a ser la protagonista en los años venideros ${ }^{37}$.

Las nuevas tecnologías al alcance de algunos de los países que nos ocupan ayudan a reducir las diferencias con la investigación producida en los países más desarrollados, pero es poco probable que en el futuro imediato los recursos técnicos y financieros disponibles en buena parte de Centroamérica y del Caribe permitan la aceleración del desarrollo a los ritmos que serían deseables.

El desequilibrio en la calidad de la investigación hispanística obedece a varias causas, que van de la ideología a la marginalidad de las minorías étnicas. Hasta ahora, la mayor parte de los estudios se ha llevado a cabo en las principales universidades de ciudades como La Habana, San Juan, San José, México, Guadalajara, Puebla... En el momento actual, varios centros, departamentos y facultades radicados en otras ciudades empiezan a plantear sus propias investigaciones de acuerdo a las necesidades de la zona. Es el caso, entre otros muchos, de Hermosillo (Sonora, México) o de Santa Clara (Cuba). Para el futuro cercano, cabe pronosticar - y desear- la aparición de nuevos focos especializados en zonas donde el desarrollo de la investigación lingüística y literaria es aún incipiente. 
Estamos seguros de que el camino para el hispanismo que aquí hemos reseñado pasa por la búsqueda de preguntas propias, nacidas de las varias realidades lingüísticas y culturales que caracterizan a los diez países estudiados. Sólo así podremos esperar la aportación de explicaciones originales que contribuyan al enriquecimiento del hispanismo.

\section{Notas}

1 Somos conscientes de la imposibilidad de ofrecer datos exhaustivos de los proyectos, líneas de investigación y publicaciones que caracterizan al hispanismo de nuestra área de estudio. Por otra parte, tampoco tendría sentido ofrecer una enumeración deshilvanada de nombres y obras, pues nuestro fin último es desentrafiar los rasgos esenciales del hispanismo en México, América Central y el Caribe.

2 Aunque sólo sea un dato indicativo, de las 475 revistas especializadas que figuran en el catálogo bibliográfico de la Nueva Revista de Filología Hispánica, unas 70 se publican en nuestra area. Entre las más destacadas, se encuentran la Nueva Revista de Filología Hispánica, el Anuario de Letras, Cuadernos Americanos, Morphé, Literatura Mexicana, La Palabra y el Hombre, Estudios de Lingüística Aplicada, Medievalia, Función y Semiosis en México; Casa de las Américas, Islas, Anuario L/L, Unión y Comunicación Social en Cuba; el Boletín de la Academia Puertorriqueña de la Lengua, la Revista de Estudios Hispánicos, La Torre y Homines en Puerto Rico; en Centroamérica las publicaciones periódicas más interesantes se concentran en Costa Rica: Káñina, Praxis y la Revista de Filología y Lingüística de la Universidad de Costa Rica.

3 Con este término nos referiremos al conjunto de los países de los que hablamos en este trabajo. Geográficamente, pertenecen en realidad a tres zonas diferentes: América del Norte, Central y el Caribe.

4 Aunque sí hay regiones, como el Caribe hispánico - Puerto Rico y la República Dominicana- que en varios sentidos parece formar una entidad. Cf. infra n. 8.

5 Sobre Henríquez Ureña puede verse ahora Alvarez Martínez 1998.

6 Dos asociaciones conjuntan aún a los lingüistas y a los estudiosos de la literatura: son la Asociación de Lingüística y Filología de la América Latina y la Asociación Internacional de Hispanistas. Sin embargo, desde hace bastantes años en la primera de estas sociedades vienen predominando los lingüistas y en la segunda los críticos e historiadores de la literatura. Existen varias asociaciones locales en nuestra área, todas ellas bastante jóvenes: la Asociación Mexicana de Lingüística Aplicada (desde 1986, aunque informalmente desde 1980), la Asociación de Estudiosos de la Semiótica (México), la de Historia de la Lingüîstica (México), la Asociación de Lingüístas de Cuba (sobre ésta, constituida en 1986, véase Figueroa 1990, p. 5), entre otras.

7 Por ejemplo, en el caso de México los hispanistas tradicionales sólo se habían interesado en las lenguas indígenas en la medida en que podían haber dejado, o no, vestigios en el español. Esta situación ha dado un viraje significativo en la actualidad.

8 Esto es también válido para la literatura. Por ejemplo, Phaf 1989 plantea la idea de una estética caribefía apoyada en el elemento negro. 


\section{El hispanismo en México, America Central y Las Antillas}

9 Esto recuerda aquella distinción entre estudiar el español de América y estudiar el español en América. Cf. Fontanella de Weinberg 1992 y Moreno de Alba 1993.

10 La relación entre la cultura afroamericana y la hispánica en las Antillas es muy diferente, en cualquier caso, a la que se da con las culturas indoamericanas en otros lugares, como México. Esto es particularmente obvio en la literatura, donde el elemento negro es un componente vivo, tanto como creación y como reflejo, mientras que los indígenas ocupan un papel marginal en la crítica y en la creación de la alta cultura mexicana.

11 Son muchos los casos pertinentes. El contacto de lenguas es frecuente y variado. Irene Pérez Guerra (1999) completa la clasificación de Fontanella de Weinberg (1996) sobre los tipos de contacto de lenguas. Para Fontanella, pueden distinguirse los contactos entre el español y las lenguas indígenas, entre el español y las lenguas africanas, contactos con otras lenguas europeas en fronteras lingüísticas, contactos con lenguas de ínmigrantes (pp. 439-440). Pérez Guerra observa, al hablar de los contactos dominico-haitianos, que «nos encontramos con un significativo desconocimiento y ausencia de investigaciones por la falta de estudios serios y de conjunto, sobre el contacto lingüístico del español caribeño y una modalidad de lengua criolla de base léxica francesa: el haitiano" (p. 320). Esta idea es pertinente para Cuba y Santo Domingo; en Puerto Rico, en cambio, el problema del contacto con el inglés debe verse más bien como un caso de imposición lingüística.

12 «Hace sesenta años don Ramón Menéndez Pidal se vio obligado a establecer, con su solo esfuerzo, un lazo sólido entre la vieja tradición española de erudición filológica y la ciencia entonces relativamente nueva de lingüística romance que se cultivaba sobre todo en el extranjero" (Malkiel 1964, p. 107). El hispanismo tradicional es quizá el que parte de la idea de que todos los estudios lingüísticos y literarios son, de alguna manera, históricos y filológicos. Pero es difícil creer que la historia sea hoy el marco de estudio en la América Media. Ello era obvio en programas como el del dominicano Henríquez Ureña, pero la historia hoy parece disgregarse.

13 Un amplio recuento actualizado de esta vieja discusión puede leerse, entre otros, en Moreno de Alba 1993.

14 En ese sentido, se trata de un hispanismo más próximo a lo expresado por Bataillon al inaugurar el Tercer Congreso Internacional de Hispanistas en la ciudad de México en 1968: "Nuestro hispanismo tiene horizontes muy amplios, ya que (...) abarca no sólo, con lo castellano, lo catalán y lo valenciano, lo vasco y lo gallego, sino también lo portugués y lo brasileño, todo lo hispanoamericano y las lenguas indígenas de América" (1970, p. xxii).

15 Los materiales del habla culta de México se encuentran en Lope Blanch 1971, y los de San Juan de Puerto Rico en Morales y Vaquero 1990; una versión electrónica de parte de los materiales de estas dos ciudades y también de los de San José de Costa Rica -entre los de otras ciudades- aparecen en Samper Padilla 1998.

16 En paralelo, en México se ha desarrollado el proyecto de estudio del habla popular, cuyos resultados contrastan con los de la norma culta y dan una idea clara de las diferencias sociodialectales.

17 Sobre México en particular, véase Barriga y Parodi 1998 y Barriga, Martín y Parodi 1999.

18 Por otra parte, se siguen publicando con profusión diccionarios de modismos, muchos de ellos apoyados en criterios más o menos normativos. El librito sobre El Salvador de Geoffroy Rivas había sido editado ya cinco veces en 1982 (la la. ed. es 
de 1969). En Costa Rica se han publicado los Problemas idiomáticos de López Martín (1982) y los Refranes de Hernández (1987); en Nicaragua el diccionario de fraseologismos de García Rodríguez (1996) ... la lista por países resultaría en realidad interminable. Por desgracia, muchos de estos trabajos no han sido redactados con el rigor que deberían. La labor de las Academias de la Lengua ha sido modesta en la mayor parte de los casos. Prácticamente nada hay de interesante, por ejemplo, en el Boletín de la Academia Hondureña de la Lengua, que se publica desde 1955. La Academia Mexicana de la Lengua ha estado más activa en los últimos tiempos; ha publicado un polémico índice de mexicanismos y tiene algunos otros proyectos en marcha. Pero la impresión general es que las Academias de nuestros países necesitarían de una profunda renovación para convertirse en verdaderos centros de investigación o por lo menos de difusión de la cultura. Lamentablemente, no tienen el peso ínstitucional, la influencia o los recursos de la de Madrid. «La colaboración prestada a la Academia matriz por sus filiales americanas termina. prácticamente en la labor lexicográfica» (p. 289), comenta Humberto López Morales en un trabajo descriptivo de la labor de las academias americanas.

19 Véase infra el apartado de Culturas mezcladas.

20 Precisamente el mismo Miguel Ángel Quesada Pacheco publicó en 1996 una buena síntesis 'de los principales rasgos del español de la América Central.

21 En el mismo marco, se están preparando otras colecciones documentales. Así, se están recogiendo materiales en el Archivo General de Cuba y en el Archivo de Indias.

22 Por lo pronto, ya se dispone de bibliografías especializadas. Los estudios lingüísticos del área están representados en varios volúmenes: el publicado en 1994 por H. López Morales sobre Las Antillas_y el de 1999 sobre América Central; y el cuaderno de 1999 de Barriga Villanueva, Martín Butragueño y Parodi sobre México.

23 Es interesante el paralelismo con la falta de estudios lingüísticos descriptivos de ciertas zonas y de ciertos períodos. ¿Es posible seguir adelante en el desarrollo de una disciplina sin esas bases?

24 Un ej emplo entre muchos es la antología Mujeres latinoamericanas: Historia y cultura. Siglos XVI al XIX (Campuzano 1997), esfuerzo conjunto de la Casa de las Américas de Cuba y la Universidad Autónoma Metropolitana de México.

25 Otro tanto puede decirse de la República Dominicana, país también marcado por una copiosa herencia africana.

26 Aunque este tipo de reflexiones son pertinentes para varios países, resulta llamativo el caso cubano, donde la posmodernidad se convierte en nueva búsqueda o redefinición de la identidad nacional (cf. Zurbano 1996).

27 «En el caso de Puerto Rico, el nacionalismo cultural se puede ver como una manifestación de un discurso paternalista más abarcador que se origina en el siglo XIX, muy ligado a una clase social -la de los hacendados-" (Gelpí 1993, p. 2) . Para la República Dominicana, véase el trabajo de Cachán 1988.

28 La revista Káñina, de San José, dedicó el número 17, 1 de 1993 al proceso de identidad latinoamericana en el centenario de Nuestra América. Martí se convierte en el paradigma de identidad latinoamericana. Por su parte, otra revista costarricense, Praxis, de Heredia, se ocupa en su número 47-48 de 1994 al problema de «Sociedad y posmodernidad". Figuran allí trabajos de título sugerente, pero de contenido algo superficial.

29 Algunos autores parecen estar alcanzando mayor resonancia a raíz de su inclusión en editoriales internacionales. Es el caso de Mario Monteforte Toledo, Marco 


\section{El hispanismo en México, America Central y Las Antillas}

Antonio Flores y Rodrigo Rey Rosa, de Guatemala, del panameño Enrique Jaramillo Levi o del contarricense Carlos Cortés.

30 Algunos pueden sospechar que el interés por la literatura testimonial viene de la mano de los llamados estudios culturales, tan de moda ahora en los Estados Unidos. Por otra parte, ya "in 1970 Casa de las Américas announced the addition of testimonial literature to the list of categories for which a writer could receive the Premio Literario" (Román-Lagunas 1994, p. vi). Un examen bastante amplio del problema puede encontrarse en los dos volúmenes que Zimmerman 1995 dedica a literatura y resistencia en Guatemala.

31 No siempre es fácil encontrar antologías recientes. Ello no impide, obviamente, que sigan siendo interesantes las que ya tienen algunos años. Véanse, por ejemplo, para Panamá, las antologías narrativa (1971) y poética (1980) preparadas por Enrique Jaramillo Levi, o la Antología de la poesía panameña editada en 1985 en Bogotá

32 Los revistas cubanas se caracterizan por un alto grado de contenido político e ideológico. Islas o Casa de las Américas_entremezclan los estudios propiamente dichos con trabajos de creación. Martí es el gran protagonista de los estudios cubanos literarios, sin que escaseen en ellos los análisis políticos, a veces bastante superficiales. No faltan trabajos sobre Carpentier, Lezama Lima, Eliseo Diego. En especial, la creación joven tiene en Cuba un lugar destacado.

33 Para una revisión descriptiva de la situación lingüística hispanoamericana, cf. Lastra 1992.

34 Cf. Spence Sharpe 1997 sobre cambio lingüístico y 1998 acerca d las actitudes de los hablantes, Herzfeld y Perry 1996 sobre los proverbios y Herzfeld 1994 en torno a la minoría negra.

35 Para esta nueva manera de ver los hechos, véanse el libro de Zimmermann sobre lenguas en contacto en Hispanoamérica (1995), el de Cifuentes sobre el multilingüismo a través de la historia (1998), y el de Coronado et al. (1999) sobre los sistemas comunicativos bilingües que se dan en algunas comunidades indígenas de los estados de México, Puebla, Michoacán, San Luis Potosí y Oaxaca (todos ellos de México).

36 Llama la atención la escạsez de estudios lingüísticos en algunos países. De Panamá, la bibliografía de López Morales 1999 cita apenas una docena de trabajos publicados en los años 90; de ellos, sólo 3 o 4 parecen haber sido escritos por panameños.

37 Entre los huecos más notorios está la falta de gramáticas que tomen como español de referencia alguna de las variedades locales.

\section{Bibliografía}

Alba, Orlando 1998. "Variable léxica y dialectología hispánica», La Torre, 7-8, pp. 299-316.

Albizúrez Palma, Francisco, y Catalina Barrios Y Barrios 1993. Historia de la literatura guatemalteca. 2a. reimpresión. Guatemala: Editorial Universitaria de Guatemala. $\left[1 .^{\text {a }}, 19811\right.$.

AlCÁntara Almánzar, José 1989-1990. «Sobre literatura dominicana, 1965-1985», Homines, 13-2, 14-1, pp. 325-332. 
Álvarez Martínez, Maria Ángeles 1998. «Pedro Henríquez Ureña y la dialectología hispanoamericana", La Torre, 7-8, pp. 177-185.

Álvarez Nazario, Manuel 1990. El habla campesina del país: origenes y desarrollo del español en Puerto Rico. Río Piedras: Universidad de Puerto Rico.

Álvarez Nazario, Manuel 1991. Historia de la lengua española en Puerto Rico. San Juan: Academia Puertorriquefia de la Lengua Española.

Antología de la poesía panameña 1985. Bogotá: Secretaría Ejecutiva Permanente del Convenio "Andrés Bello".

Arias Álvarez, Beatriz 1997. El español de México en el siglo XVI (Estudio filológico de quince documentos). México: UNAM.

Barradas, Efraín (de.) 1983. Apalabramiento. Cuentos puertorriqueños de hoy. Hanover: Ediciones del Norte.

Barriga, Rebeca, y ClaudiA Parodi 1998. La lingüistica en México 1980-1996. México: El Colegio de México - Los Angeles: UCLA.

Barriga, Rebeca, Pedro Martín, y Claudia Parodi 1999. El español de América. Cuadernos bibliográficos. 9: México. Madrid: Arco/Libros.

Batallon, Marcel 1970. [Alocución], en Actas del Tercer Congreso Internacional de Hispanistas, celebrado en México D.F., del 26 al 31 de agosto de 1968. Ed. Carlos H. Magis. México: El Colegio de México, pp. xxi-xxiv.

Bonilla, Abelardo 1967. Historia de la literatura costarricense. San José: Editorial Costa Rica.

CACHÁN, MANUEL 1988. «Presencia del movimiento mesiánico en la literatura dominicana», Revista Iberoamericana, 142, pp. 53-62.

Campuzano, LuIsa (coord.) 1997. Mujeres latinoamericanas: Historia y cultura. Siglos XVI al XIX. La Habana: Casa de las Américas - Universidad Autónoma Metropolitana, 2 ts.

Cifuentes, Bárbara 1998. Letras sobre voces. Multilingüismo a través de la historia. México: Centro de Investigaciones y Estudios Superiores en Antropología Social - Instituto Nacional Indigenista.

Company Company, Concepción 1994. Documentos lingüísticos de la Nueva España. Altiplano Central. Pról. Juan M. Lope Blanch. México: UNAM.

Coronado SuzÁn, Gabriela, et al. 1999. Porque hablar dos idiomas ... es como saber más. Sistemas comunicativos bilingües ante el México plural. México: Centro de Investigaciones y Estudios Superiores en Antropología Social - Secretaría de Educación Pública - Consejo Nacional de Ciencia y Tecnología.

Cortés, Carlos 1998. Cruz de olvido. México: Alfaguara.

Dobles, Fabián 1993. Obras completas. San José: Universidad de Costa Rica, 5 ts.

Dominguez Michael, Christopher 1989. Antología de la narrativa mexicana del siglo $X X$. México: FCE.

Elvir Rojas, Felipe (ed.) s.f. Antología del soneto en Honduras. Tegucigalpa: Pegaso.

Fernández Retamar, Roberto 1988. Recuerdo a. La Habana: Ediciones Unión.

FigueroA, Max 1990. "La lingüística en Cuba: balance y perspectivas", Nueva Revista de Filología Hispánica, 38, pp. 1-13.

Flores, Marco Antonio 1996. Los muchachos de antes. México: Alfaguara.

Fontanella de Weinberg, M. ${ }^{a}$ Beatriz 1992. El español de América. Madrid: Mapfre.

Fontanella de Weinberg, M. ${ }^{a}$ Beatriz 1996. «Contacto lingüístico: lenguas inmigratorias», en Contactos y transferencias lingüisticas en Hispanoamérica. Una perspectiva va- 


\section{El hispanismo en México, America Central y Las Antillas}

loradora desde Hispanoamérica. Comp. Germán de Granda. Buenos Aires: Universidad de Buenos Aires, pp. 439-457. [Monográfico de Signo y Seña, 6].

Galindo, David Escobar (ed.) 1987. Índice antológico de la poesía salvadoreña. 2. ${ }^{\mathrm{a}}$ ed. San Salvador: UCA.

Gallegos Valdés, Luis 1962. Panorama de la literatura salvadoreña. 2. ${ }^{a}$ ed. San Salvador: Ministerio de Educación.

García Riverón, RaQUel 1991. “El Atlas Lingüístico de Cuba», Lingüística Española Actual, 13, pp. 199-201.

Garcia Rodriguez, Reina (dir.) 1996. Breve diccionario de fraseologismos. Managua: Distribuidora Cultural.

García S., Ismael 1972. Historia de la literatura panameña. México: UNAM.

Garza Cuarón, Beatriz, y Georges Baudot (eds.) 1996. Historia de la literatura mexicana desde sus orígenes hasta nuestros días. Vol. I: Las literaturas amerindias de México y la literatura en español del siglo XVI. México: UNAM - Siglo XXI.

Gelpí, Juan G. 1993. Literatura y paternalismo en Puerto Rico. San Juan: Editorial de la Universidad de Puerto Rico.

Geoffroy Rivas, Pedro 1982. El español que hablamos en El Salvador. 5. ${ }^{\text {a }}$ ed. San Salvador: Ministerio de Educación.

González Peña, Carlos 1928. Historia de la literatura mexicana. México: Porrúa.

Granda, GeRmÁn DE 1987. «Situación actual de los estudios lingüísticos afrohispanoamericanos», Thesaurus, 42, pp. 60-94.

Granda, Germán DE 1994. Español de América, español de África y hablas criollas hispánicas. Cambios, contactos y contextos. Madrid: Gredos.

Guillén, Orlando 1989. Hombres como madrugadas: la poesía de El Salvador. 2. ad. México: UAM.

Herzfeld, ANita 1994. "Language and identity: The Black minority of Costa Rica", Revista de Filolología y Língüística, 20, 1, pp. 113-142.

Herzfeld, Anita, y Franklin Perry 1996. "Limonese creole provebrs and sayings», Revista de Filología y Lingüística, 22, 1, pp. 155-193.

Hernández H., Hermógenes 1987. Refranes y dichos populares. San José: Alma Mater.

Herranz, ATANASIO 1990. "El español de Honduras a través de su bibliografía», Nueva Revista de Filología Hispánica, 38 pp. 15-63.

Herranz, Atanasio 1996. Estado, sociedad y lenguaje. La política lingüística en Honduras. Tegucigalpa: Guaymuras.

Homenaje a Diana Morán. Poetisa panameña 1990. México: Universidad Autónoma Metropolitana.

Hurtado Heras, Saúl 1997. Por las tierras de Ilóm. El realismo mágico en Hombres de maíz. México: Universidad Autónoma del Estado de México.

Jaramillo Levi, EnRique (ed.) 1971. Antologia crítica de joven narrativa panameña. México: Federación Editorial Mexicana.

Jaramillo Levi, Enrique (ed.) 1980. Poesía panameña_contemporánea (1929-1979). México: Liberta-Sumaria.

Jaramillo Levi, EnRique 1998. Caracol y otros cuentos. México: Alfaguara.

Jiménez RuedA, Julio 1928. Historia de la literatura mexicana. México: Ediciones Botas.

Lara Ramos, Luis Fernando (dir.) 1986. Diccionario básico del español de México. México: El Colegio de México. 
Lara Ramos, Lus Fernando (dir.) 1993. Diccionario fundamental del español de México. México: FCE.

Lara Ramos, Luis Fernando (dir.) 1996. Diccionario del español usual en México. México: El Colegio de México.

Lastra, Yolanda 1992. Sociolingüistica para hispanoamericanos. Una introducción. México: El Colegio de México.

LÁzaro, Felipe y Bladimiro Zamora 1994. Poesía cubana: la isla entera (Antología). Madrid: Betania.

Lazo, RaImundo 1974. Historia de la literatura cubana. $2 .^{\mathrm{a}}$ ed. México: UNAM.

LipSK, John M. 1989. The Speech of the Negros Congos of Panama. Amsterdam Philadelphia: John Benjamins.

Lope Blanch, Juan M. (ed.) 1971. El habla de la ciudad de México. Materiales para su estudio. México: UNAM.

Lope Blanch, Juan M 1985. El habla de Diego de Ordaz. Contribución al estudio del español americano. México: UNAM.

Lope Blanch, Juan M (dir.) 1990-2000. Atlas Lingüistico de México. México: El Colegio de México - FCE - UNAM, 6 ts.

López Berrios, Maritza y Everardo Mendoza Guerrero 1997. El habla de Sinaloa: materiales para su estudio. Prólogo de José G. Moreno de Alba. Culiacán: Universidad Autónoma de Sinaloa - El Colegio de Sinaloa.

López Martín, Alfonso 1982. Problemas idiomáticos del habla costarricense. San José: Universidad de Costa Rica.

López Morales, Humberto 1992. "Las academias americanas», en La lengua española, hoy. Coord. Manuel Seco y Gregorio Salvador. Madrid: Fundación Juan March, pp. 281-290.

López Morales, Humberto 1994. El español de América. Cuadernos bibliográficos. 3: Las Antillas. Madrid: Arco/Libros.

López Morales, Humberto 1999. El español de América. Cuadernos bibliográficos. 2: América central. Madrid: Arco/Libros.

MALKIEL, YAKov 1964. "Filología española y lingüística general», en Actas del Primer Congreso Internacional de Hispanistas. Ed. Frank Pierce y Cyril A. Jones. Oxford: The Dolphin Book, pp. 107-126.

Miguel Muñoz, Elfas 1988. Desde esta orilla: poesía cubana del exilio. Madrid: Betania.

Miró, RodRIGo 1971. La literatura panamena (origen y proceso) Panamá: Manfer. [Reimpr. en 1981].

Monteforte Toledo, Mario 1996. Unas vísperas muy largas. México: Alfaguara.

Morales, Amparo, y Marfa Vaquero (eds.) 1990. El habla culta de San Juan. Materiales para su estudio. San Juan: Universidad de Puerto Rico.

Morales Santos, Francisco (ed.) 1990. Nueva poesía guatemalteca. Caracas: Monte Avila.

Morán Garay, Diana Elsa 1989a. Poesía. Ed. Margarita García Alonso. La Habana: Casa de las Américas.

Morán Garay, Diana Elsa 1989b. Soberana presencia de la patria y otros poemas. Ed. Jorge Turner. México: Universidad Autónoma Metropolitana.

Moreno de Alba, José G. 1993. El español en América. 2. ${ }^{a}$ ed. México: Fondo de Cultura Económica.

Ochando Aymerich, Carmen 1998. La memoria en el espejo. Aproximación a la escritura testimonial. Barcelona: Anthropos. 


\section{El hispanismo en México, America Central y Las Antillas}

Ortega, Julio 1991. Reapropiaciones (Cultura y nueva escritura en Puerto Rico). San Juan: Editorial de la Universidad.

Ortiz López, Luis A. (ed.) 1998a. El Caribe hispánico: perspectivas lingüísticas actuales. Frankfurt: Vervuert - Madrid: Iberoamericana.

Ortiz LóPez, Luis A. (ed.) 1998b. Huellas etno-sociolingüísticas bozales y afrocubanas. Frankfurt: Vervuert - Madrid: Iberoamericana.

Ovares, Flora, et al. 1993. La casa paterna. Escritura y nación en Costa Rica. San José: Universidad de Costa Rica.

Oviedo, Jorge Luis 1993. Antología del cuento hondureño. 3. ${ }^{\text {a }}$ reimpr. Tegucigalpa: Editores Unidos.

Padura, Leonardo (ed.) 1993. El submarino amarillo. (Cuento cubano 1966-1991). Breve antología. México: UNAM - Ediciones Coyoacán.

Parodi, Claudia 1995. Orígenes del español americano. Vol. I: Reconstrucción de la pronunciación. México: UNAM.

Paz, Octavio 1994. Obras completas, vol. I. México: FCE.

Pérez Guerra, Irene 1999. “Contacto lingüístico dominico-haitíano en República Dominicana: Datos para su estudio", en El Caribe hispoánico: Perspectivas lingüísticas actuales. Homenaje a Manuel Alvarez Nazario. Ed. Luis A. Ortiz L6pez. Frankfurt: Vervuert - Madrid: Iberoamericana, pp. 317-321.

Perl, Matthias, Y Armin Schwegler (eds.) 1998. América negra: Panorámica actual de los estudios lingüisticos sobre variedades hispanas, portuguesas y criollas. Frankfurt: Vervuert - Madrid: Iberoamericana.

PHAF, INEKE 1989. «Perspectiva caribeña y percepción nacional en la literatura urbana del Caribe hispanohablante: Cuba, Puerto Rico V República Dominicana", Homines, 13, 1, pp. 59-70.

Pineda Reyes, Rafael 1989. Análisis de dos obras de la literatura auatemalteca contemporánea. Mister Taylor de Augusto Monterroso y El remolino de Ricardo Estrada. Guatemala: Universidad de San Carlos.

Quesada, Alvaro, et al. 1993. Antología del teatro costarricense 1890-1950. Selección., introducción., notas y bibliografía. San José: Universidad de Costa Rica.

Quesada Pacheco, Miguel Angel 1990. El español colonial de Costa Rica. San José: Universidad de Costa Rica.

Quesada Pacheco, Miguel Angel 1991a. El español de Guanacaste. San José: Universidad de Costa Rica.

Quesada Pacheco, Miguel Angel 1991b. Nuevo diccionario de costarriqueñismos. Cartago: Editorial Tecnológica.

Quesada Pacheco, Miguel Angel 1991c. El español de Costa Rica. Historia de sus estudios filológicos y lingüísticos. San José: Fernández Arce.

Quesada Pacheco, Miguel Angel 1992. "Pequeño Atlas lingüístico de Costa Rica», Revista de Filología y Lingüística, 18, pp. 85189.

Quesada Pacheco, Miguel Angel 1996. «El español de América Central», en Manual de dialectoloqía hispánica. El español de América. Dir. Manuel Alvar. Barcelona: Arielf Dp. 101-115.

REY Rosa, Rodrigo 1996. El cojo bueno. Madrid: Alfaguara.

Román-Laqunas, Victoria ANN 1994. Latin American Testimonial Narrative, A "New» Genre: A Studv of La montaña es algo más que una inmensa estepa verde, I, Rigoberta Menchú, and Tejas Verdes. Tesis doctoral. The Florida State University. 
[Las obras son, respectivamente, de Omar Cabezas (Nicaragua), Rigoberta Menchú (Guatemala) y Hernán Valdés (Chile)].

Rosado, José Ángel (ed.) 1995. El rostro y la máscara. Antología alterna de cuentistas puertorriqueños contemporáneos. San Juan: Isla Negra - Universidad de Puerto Rico.

Samper Padilla, José Antonio (ed.) 1998. Macrocorpus de la norma lingüística culta de las principales ciudades de España y América. Las Palmas: Universidad de Las Palmas de Gran Canaria, 1 CD.

Sánchez Corrales, Víctor 1998. «Nuevo diccionario del español de Costa Rica, elementos léxicos constitutivos peninsular-europeos», Káñina, 22, pp. 109-121.

Spence Sharpe, Marva 1997. «A case studv of language shift in progress in Port Limon, Costa Rica", Revista de Filología y Lingüistica, 23, pp. 225-234.

Spence Sharpe, Marva 1998. "Language attitudes of Limon Creole speakers", Revista de Filología y Lingüística, 24, pp. 101-112.

Toruño, Juan Felipe 1957. Desarrollo literario de El Salvador. San Salvador. Ministerio de Cultura.

ZavalA, LaUro 1998. La palabra en juego. El nuevo cuento mexicano. Toluca: Universidad Autónoma del Estado de México.

Zimmerman, Marc 1995. Literature and Resistance in Guatemala. Textual Modes and Cultural Politics from. El señor Presidente to Rigoberta Menchú. Vol. I: Theory, History, Fiction and Poetry. Vol. II: Testimonio and Cultural Politics in the Yeras of Cerezo and Serrano Elías. Athens: Ohio University Center for International Studies.

Zimmermann, Klaus 1995. Lenguas en contacto en Hispanoamérica. Nuevos enfoques. Madrid: Iberoamericana - Frankfurt: Vervuert.

ZuRbano, Roberto 1996. Los estados nacientes. Literatura cubana y posmodernidad. La Habana: Letras Cubanas. 